\title{
CAMINHOS DA BIOGEOGRAFIA
}

Pedro Germano Murara

Professor Assistente da Universidade Federal da Fronteira Sul, Erechim (RS) pedro.murara@uffs.edu.br

Recebido em: 03/09/2015; Aceito para publicação em: 02/06/2016

\section{RESUMO}

A Biogeografia, enquanto ramo da Ciência Geográfica, estuda a distribuição das espécies animais e vegetais, o que lhe confere como características uma visão sob o foco ambiental na Geografia. No entanto, seu aporte teórico-metodológico ainda permanece baseado nas concepções biológica de análise e desta forma, pouco explora as relações entre a natureza e a sociedade. Este artigo reporta a favor de avanços teóricos na concepção da Biogeografia a luz da história e trajetória na Ciência. Por trata-se de um estudo de cunho teórico-investigativo adotou-se como materiais fontes bibliográfica. Enquanto professores e pesquisadores cabe-nos refletir sobre 0 atual avanço nas concepções e pesquisas da Biogeografia, identificando novas variáveis que possam ser incorporadas nos estudos biogeográficos.

Palavras-chave: Epistemologia; Ensino; Geografia Física

\section{WAYS OF BIOGEOGRAPHY}

\begin{abstract}
The Biogeography in the Geographic Science, studies the distribution of animal and plant species, featuring a vision from an environmental focus on geography. However, its theoretical and methodological support is still based on biological concepts of analysis and thus little explores the relationships between nature and society. This article reports in favor of theoretical advances in the design of Biogeography the light of history and career in science. For it is a theoretical and investigative nature of the study was adopted as materials bibliographical sources. While teachers and researchers it is up to us to reflect on the current advances in concepts and research of biogeography, identifying new variables that can be incorporated in biogeographical studies.
\end{abstract}

Keywords: Epistemology; Education; Physical Geography 


\title{
INTRODUÇÃO
}

De abordagem ampla e complexa, a Biogeografia abarca vários campos disciplinares dentre os quais destacam-se a Geografia, Biologia, Ecologia, Paleontologia, Geologia, Zoologia entre outros (KUHLMANN, 1977; CAMARGO, 2004; BROWN e LOMOLINO, 2006; ROCHA, 2011). Essa característica confere-lhe atuações distintas resultando em abordagem biogeográfica com as mais variadas perspectivas de investigação. Desta forma, seu objeto de pesquisa muitas vezes se torna impreciso e não consensual em vista das diferentes abordagem que o estudo em Biogeografia executa nos seus campos de análise.

\begin{abstract}
What it depends on is whether biogeographers are interested in plants or in animals. If in animals, it depends on whether these creatures are marine or terrestrial. It depends also on the spatial scale studied, whether local, regional, or continental. Further, it depends on the temporal frame a biogeographer considers, whether short-term, Pleistocene, or encompassing distant epochs. Finally it depends on whether a biogeographer is interested in ecological causation (ecological biogeography) or in phylogenetic history (historical biogeography). Regardless of the actual focus, however, what is biogeographers work on are species. (VUILLEUMIER, 1999, p. 4 apud ANDRADE, 2012).
\end{abstract}

Na Ciência Geográfica, de modo geral, a Biogeografia é definida como o estudo da distribuição, adaptação e a explicação dos seres vivos - animais e vegetais - no espaço geográfico (CAMARGO, 2000). Desta forma, seu objetivo está intrinsecamente associado a uma visão ampla e complexa das relações e correlações dos aspectos da natureza com o Homem e/ou dos ambientes com a sociedade. A abordagem da Biogeografia efetuada por Geógrafos necessita evocar o caráter social (ALBUQUERQUE et al., 2004), uma vez que a Ciência Geográfica é uma Ciência Humana e, nesta caso, possui como partida para suas análises os componentes da natureza.

No entanto, a Biogeografia não apresenta a mesma notoriedade quando comparada com as demais áreas de enfoque ambiental da Ciência Geográfica como a Geomorfologia, Climatologia, Hidrogeografia, etc., de modo que a Biogeografia tem sido ensinada e lecionada sob um forte aspecto dos estudos da Biologia e da Ecologia, muitas vezes confundindo-se com as mesmas (CAMARGO, 2004).

Alguns autores chegam a afirmam que a Biogeografia é um ramo da Biologia, e que "naturalmente é importante conhecer algo sobre Geografia" (BROWN e LOMOLINO, 2006, p. 5). Outros, buscam novas concepções e pesquisa da Biogeografia, objetivando incorporar nos seus estudos novas variáveis que possam "torná-la mais próxima da Geografia e do mundo de nosso tempo" (ALBUQUERQUE et al., 2004).

Neste breve contexto é possível afirmar que a Biogeografia apresenta-se em crise quanto ao seu escopo investigativo na Ciência Geográfica, uma vez que, ainda no século XXI se discuta o seu objeto de estudo, suas perspectivas e atuações por parte dos Geógrafos.

Neste sentido, faz-se necessário um resgate histórico e teórico do desenvolvimento da Biogeografia na Ciência Geográfica para então se pensar em novas perspectivas e abordagens da Biogeografia na atualidade.

\section{GÊNESIS DA BIOGEOGRAFIA}

Embora a Ciência Geográfica tenha surgido somente em meados de 1750 (MOREIRA, 1994) é possível pensar em uma Biogeografia anterior à existência da própria Geografia enquanto Ciência, que já se ocupava em explicar a distribuição dos seres vivos no espaço e correlacionálas com os aspectos do ambiente e com o homem, em uma visão ampla e complexa (CAMARGO e TROPPMAIR, 2002).

$\begin{array}{lllll}\text { Caminhos de Geografia } \quad \text { Uberlândia } & \text { v. 17, n. } 58 \quad \text { Junho/2016 } & \text { p. 168-179 } & \text { Página } 2\end{array}$


Se levarmos em consideração as pinturas rupestres efetuadas pelos homens pré-históricos que já buscavam por meio de ilustrações retratar o ambiente e os animais, desta forma, podemos pensar em uma Biogeografia pré-histórica, na qual, os registros e descrições em cavernas e paredões rochosos das atividades humanas e das observações dos seres vivos se constituem como os primeiros "estudos" da distribuição de seres vivos.

Ciências como a Arqueologia, Paleontologia, Zoologia, Antropologia e a própria Biogeografia utilizam-se destas descrições e destes registros para aferir análises da distribuição de espécies, formas de organização (social e de espécies), assim como, compreender a evolução da vida. Portanto, esse resgate às pinturas rupestres, efetuado principalmente pela Arqueologia, já constitui os primórdios que sustentarão o futuro Biogeografia.

Porém, é com a civilização greco-romana (1.100 a.C. e 400 d.C.), que desenvolvendo notável conhecimento científico deixará na história uma vasta quantidade de trabalhos sobre os mais variados assuntos, incluindo a Biogeografia (CAMARGO, 1998; D'HORTA, 2009). Theophrasto ou Teofrasto (327-288 a.C.), aluno e sucessor de Aristóteles, deve ser lembrado pela sua atuação nas observações das formas de crescimento dos vegetais, destacando a importância e a influência do clima para o processo de desenvolvimento das plantas.

O estudioso produziu os pilares do tratado da ciência botânica constituindo na mais importante contribuição da antiguidade até o Renascimento. Suas obras que merecem destaque são: Historia Plantarum (História das Plantas), em nove livros (originalmente dez), no qual o autor organiza por meio da forma e realiza uma classificação biológica das plantas de modo enciclopédico, onde um esboço de taxonomia é traçado; De Causis Plantarum (Sobre as Causas das Plantas), em seis livros (originalmente oito), que constituem em estudos sobre a descrição, reprodução, crescimento e localização de algumas espécies de plantas, e ainda, introduzindo a ideia de alterações dos ambientes e suas repercussões nos vegetais.

Theophrasto também efetuou pesquisas comparativas entre vegetações como, a região dos prados (na Macedônia) e as montanhas adjacentes das ilhas de Creta, sendo considerado portanto, como a gênese dos estudo sistemático das plantas (CAMARGO, 1998; ANDRADE, 2012).

Durante o período conhecido como Idade Média (século $V$ ao século $X V$ ) os estudos sob o enfoque da Biogeografia apresentaram seu desenvolvimento pautados primordialmente na observação, descrição e classificação das espécies. Embora, neste período, as técnicas utilizadas sejam mais elaboradas quando comparada com os registros pré-históricos, 0 progresso da investigação foi reprimido por forças religiosas.

\begin{abstract}
"Nesta época, que a historiografia faz conhecer por "Idade das Trevas", houve grande expansão do Cristianismo, que passou a ser a religião dominante, conferindo aos padres e monges o domínio do conhecimento. A ideologia religiosa cristã impôs que a natureza era uma entidade criada por Deus" (ANDRADE, 2012, p. 20).
\end{abstract}

A "Idade das Trevas", não permitia o estudo científico e, portanto, ao homem não cabia fazer qualquer especulação ou observação da natureza. Desta forma, a produção do conhecimento existente até então torna-se aprisionado nas mãos dos religiosos que passam a disseminar as concepções bíblicas a respeito da evolução e origem do homem.

"[...] Deus teria criado originalmente todas as espécies (entidades imutáveis, por saírem perfeitas das mãos do Criador) de animais num único ponto da face da Terra - O Jardim do Éden, de onde se dispersaram, após o pecado original do primeiro casal de humanos, para ocupar o resto do planeta" (CARVALHO e ALMEIDA, 2010, p. 5). 
Papavero e Teixeira (2003) destacam como primeira teoria da Biogeografia o episódio bíblico no qual Noé em sua barca refugia casais de diferentes espécies de animais, a fim de salvá-los do dilúvio, por ordem divina. "Após o Dilúvio, o Monte Ararat, onde parou a arca de Noé, funcionou como um segundo centro de origem (o primeiro seria o Jardim do Éden) e dispersão dos animais salvos pelo patriarca, que tornaram a povoar toda a superfície de nosso planeta" (CARVALHO e ALMEIDA, 2010, p. 5). Essa e outras teorias foram aceitas como um fenômeno universal de forma pacífica entre os pensadores e filósofos naturais da Europa cristã.

Ao entrar na Idade Moderna (século XVI ao século XVIII), as viagens de expedição e descobrimento de novas porções de terra colocam em cheque as concepções bíblicas. Uma vez que os viajantes deparavam-se no Novo Mundo (descobrimento da América) com uma biota muito semelhante ao Velho Mundo, e ainda, com a presença de espécies muito diferentes (porcos e macacos) e outras totalmente desconhecidas pelos europeus (marsupiais), estes não souberam inicialmente explicar como animais incapazes de voar ou nadar chegavam às ilhas oceânicas e terras do novo continente oriundas do Velho Mundo (CARVALHO e ALMEIDA, 2010).

Uma vez que o Criador (Deus) originou todas as espécies e estas por suas vez eram imutáveis, consideradas perfeitas, nunca mudavam (evoluíam) ou eram extintas, o fato de haver novas espécies na América foi explicado inicialmente pela presença de uma ponte intercontinental que ligaria a Europa à América, sustentada pela tese de ser Atlântida, a cidade que tornou-se posteriormente submersa, desconectando essa passagem. A hipótese de Atlântida foi refutada por "D'Acosta ao postular uma passagem pelo estreito de Bering, através do qual os animais provindos do Monte Ararat puderam chegar à América" (CARVALHO e ALMEIDA, 2010, p. 5).

A concepção de um centro de origem dispersor de espécies já se manifestava enquanto teoria biogeográfica, mesmo que entendida a partir de concepções bíblicas. A Biogeografia era então desenvolvida principalmente pelos europeus a partir de estudos excepcionalmente descritivos, baseados em narrativa dos lugares, constituindo-se em verdadeiros "retratos escritos" dos espaços (MENDONÇA, 2001).

Neste contexto, estavam lançadas as bases que dariam suporte para formação da Ciência Geográfica em meados do século XVIII (MOREIRA, 1994).

\section{O NASCER DA BIOGEOGRAFIA GEOGRÁFICA}

Embora as pesquisas e os estudos efetuados até o século XVIII já apontem para o surgimento de análises em Biogeografia, seu desenvolvimento e estabelecimento na Ciência Geográfica concedeu-Ihe certo status e relevância a partir dos trabalhos executados por Alexander Von Humboldt (1769-1859), no qual a Biogeografia ganhará forma acadêmica e escola sob o enfoque ecológico/naturalista.

Humboldt que conheceu a América do Sul por meio de expedição científica, realizou em diversas partes do continente observações e registros da fauna e flora procurando relacioná-los com outros elementos da natureza - clima, relevo, solo, etc. O estudioso objetivava compreender as "causas" que regiam a distribuição das espécies nas regiões tropicais que visitará (MENDONÇA, 2001; NETO e ALVES, 2010).

Deve-se a Humboldt a origem de diversas bases para a Geografia Física (ou análises geográficas do ambiente), como em climatologia, biogeografia, oceanografia, geologia etc., uma vez que produziu diversos documentos que caracterizavam e serviram como base para a formação da Geografia como Ciência (MENDONÇA, 2001).

Camargo \& Troppmair (2002) atribuem a Humboldt o desenvolvimento de um método de estudo para às ciências naturais, o empirismo raciocinado, também utilizado por outros viajantes naturalistas, que busca por meio das observações e mensuração precisa dos fenômenos, proceder para a identificação e generalização das relações aparentemente desconexas da natureza (NETO e ALVES, 2010).

Humboldt merece destaque pois, em um momento que os argumentos referentes à origem e evolução das espécies eram pautados no criacionismo, herança do poder centralizado do

$\begin{array}{lllll}\text { Caminhos de Geografia } \quad \text { Uberlândia } & \text { v. 17, n. } 58 \quad \text { Junho/2016 } & \text { p. 168-179 } & \text { Página } 4\end{array}$


catolicismo o estudioso lança a proposta de uma análise dos componentes da natureza de forma integrada.

Neste mesmo período (final do século XVIII e início do século XIX) são desenvolvidos estudos evolucionistas por Lamarck (1809) e Wallace e Darwin (1859) que ganham caráter eminentemente científico sobre a ocorrência e distribuição espacial das espécies.

Alguns autores (CAMARGO e TROPPMAIR, 2002; FURLAN, 2009), defendem que um dos grandes saltos qualitativos para o progresso da Biogeografia ocorre justamente a partir do fim do século XVIII em virtude do desenvolvimento da Biologia Evolucionista de Darwin, e da Ecologia. Drouin (1996) destaca a quantidade de argumentos que Charles Darwin buscou na Biogeografia para amparar sua teoria evolucionista apresentada na sua grande obra A Origem das Espécies.

A partir de Darwin surgem estudos na perspectiva da dispersão das espécies (dispersionismo), com destaque para o botânico italiano Léon Camille Marius Croizat forneceu uma das principais ideias que contribuíram para revolucionar a biogeografia e a evolução: a Panbiogeografia. Trata-se de um método basicamente consiste em cartografar distribuições de organismos em mapas e conectar as áreas de distribuições disjuntas ou localidades de coleta com linhas, as denominadas tracks (BROWN e LOMOLINO, 2006; MIRANDA e DIAS, 2012).

É verdade que a Biogeografia, enquanto disciplina deve sua denominação ao Geógrafo alemão Friedrich Ratzel que a teria utilizado pela primeira vez em 1880. Ratzel em sua proposta pretendia romper com antigas denominações como "geografia das plantas", "geografia botânica" ou "geografia da história natural" utilizadas por L. F. Kämtz, A. von Humboldt ou F. von Richthofen (CARVALHO, 2005).

Friedrich Ratzel em sua celebre obra Antropogeografia, escrita nos fins do século XVIII e publicada por volta de 1909, propunha uma nova abordagem da Biogeografia sustentada em uma visão integrada ao social. No período de lançamento de sua obra, não era incluído nos estudos Geográfico, o homem como fenômeno da natureza. Não se pensavam as ações humanas como modificadoras e/ou destruidoras do ambiente, daí a importância de Ratzel e sua grande contribuição para os estudos em Biogeografia por meio da integração do homem à natureza.

Portanto, deve ser creditado ao pioneirismo ratzeliano os esforços de biogeógrafos atuais no sentido de incluir a ação humana entre os principais elementos a serem considerados nas análises das biocenoses e dos ecossistemas. E, é nesse sentido que identifica-se o indicativos de uma necessidade crescente, manifestada por alguns pesquisadores da atualidade, em se conferir maior conteúdo geográfico aos interesses de estudo da Biogeografia.

Destaca-se nesta perspectiva que Ratzel já no século XVIII buscava visão integradora da Ciência Geográfica. O autor estabelecia, portanto, que a Biogeografia estaria responsável pelo estudo dos elementos bióticos (animais e vegetais), diferenciando-se significativamente da perspectiva Biológica, pois além de considerar o componente espacial na suas análises, destacava a forte influência das ações antrópicas na transformação da fisionomia da vida na Terra (ALBUQUERQUE et al., 2004).

"O geógrafo alemão pretendia o estabelecimento de uma biogeografia universal, que se oferecesse como instrumento alternativo às fragmentações promovidas pelos estudos especializados de flora e fauna, sobretudo quando estes se desenvolvem excluindo a ação humana, ou antropogeográfica, da esfera de suas preocupações" (CARVALHO, 2004, p. 03).

Dessa forma, Ratzel propõe a Biogeografia Universal, estreitamente vinculada à Antropogeografia, pois entendia que as vidas animal, vegetal e humana eram interdependentes. 


\begin{abstract}
"A nossa ciência tem que estudar a Terra unida, como ela é, incluindo o homem, por isso não pode afastar-se do estudo da vida humana, e nem mesmo do da vida vegetal e animal. As mútuas relações existentes entre a Terra e a vida, que nela se produz e se desenvolve, constituem precisamente o nexo entre uma e outra e portanto devem ser especialmente consideradas" (RATZEL, 1914 apud CARVALHO, 2004, p. 04).
\end{abstract}

Contudo, a proposta ratzeliana encontra neste mesmo período o surgimento da "escola francesa" por meio da teoria do possibilismo, e portanto verá aos poucos seu declínio quanto "escola alemã" hegemônica (MOREIRA, 1994).

O Geógrafo francês Paul Vidal de La Blache (1845-1918) é quem personificará os estudos geográficos da "escola francesa" que, embora mantenha o empirismo da "escola alemã", passará por profundas transformações na sua estruturação que nas palavras de Moreira (1994) "ganhará sua imagem atual semelhante a um armário".

Inicialmente dividida na análise dos aspectos físicos e humanos, a Ciência Geográfica sucumbirá frente a uma série de subdivisões que, tomarão como bases para sua investigação outras ciências. Neste contexto, a Biogeografia irá, com base na Biologia seguir sua trajetória de pesquisa ao lado das "componentes irmãs" como climatologia, geomorfologia, hidrografia (todas de caráter ambiental), resultando no conhecimento geográfico fragmentado que conhecemos na atualidade.

Os Geógrafos estudiosos da Biogeografia seguirão pelas ciências naturais utilizando-se do método descritivo-indutivo para suas análises e, pautados sob uma perspectiva Biológica, irão pouco a pouco negando-se a uma maior reflexão quanto as suas relações com o social. Desta forma, a Biogeografia irá perder espaço dentro da Ciência Geográfica para as suas "componentes irmãs" que embora pautadas ou baseadas em outras ciências, traçaram suas próprias características (CAMARGO, 1998; 2004).

Apenas para citar exemplo das demais divisões dos aspectos físicos da Geografia, a Geomorfologia ganha destaque a partir da forte influência da geologia estrutural, sendo a primeira a individualizar-se na Geografia Física. Autônoma, a geomorfologia segue seu próprio caminho a partir do geólogo norte-americano William Morris Davis, o pai da Teoria do Ciclo Geográfico do Relevo, que, a partir da geologia clássica ressalta a importância das transformações a que o modelado do relevo está submetido.

A climatologia, marcada por uma vasta documentação estatística e análise dos elementos climáticos e suas gêneses, avançará ao longo dos anos, adquirindo novos rumos a partir da meteorologia e, em direção a uma climatologia de caracterização e identificação de climas zonais e regionais até chegar em uma climatologia dinâmica, focada na sua relação com o social.

Outro exemplo, seria a hidrografia, concebida por diversas nomenclaturas - Hidrogeografia, Geografia das Águas ou ainda Recursos Hídricos - o estudo das águas pela Ciência Geográfica irá encontrar respaldo na observações efetuadas por Engenheiros e Agrônomos, principalmente, e baseada no escoamento superficial, processos erosivos e na geomorfologia dinâmica reforçar seu caráter inovador na Ciência Geográfica.

A Biogeografia no entanto irá beber de fontes da Biologia, como por exemplo, o método para classificação natural, a cladística, originária do entomólogo alemão Will Henning (1950). Da Botânica, utilizará de todo o conhecimento da classificação e distribuição das plantas a partir dos estudos de Teofrasto (327-288 a.C.), assim como, se aproximará da Zoologia e por consequência mergulhará nos estudos da evolução das espécies a partir de Darwin, tomando a obra A Origem das Espécies (1859) como principal referência.

Outras áreas do conhecimento como Arqueologia, Antropologia e ainda, Geologia embasaram as análises Biogeográficas e neste contexto de complexidade empreendida pelas demais ciências, a Biogeografia sucumbirá a inserção do social em suas análises. Ao mesmo tempo em que poucos Geógrafos de formação se dedicarão ao seu estudo sendo suas análises efetuada por profissionais de outras naturezas. "O pouco interesse dos geógrafos para com a

$\begin{array}{llllll}\text { Caminhos de Geografia } & \text { Uberlândia } & \text { v. 17, n. } 58 \quad \text { Junho/2016 } & \text { p. 168-179 } & \text { Página } 6\end{array}$


Biogeografia já tem se tornado tradicional e é por isso que o geógrafo Carlos A. F. Monteiro não cansa de dizer que a Biogeografia é a "filha enjeitada da Geografia Física" (CAMARGO, 2004, p. 96).

Outro ponto que merece destaque para a não equidade da produção da Biogeografia com as demais áreas de enfoque ambiental na Ciência Geográfica é a complexidade que este ramo exige. Faz-se necessários o conhecimento básicos das áreas de Biologia e Ecologia que integradas com as questões de ordem social configuram-lhe 0 enfoque Geográfico (CAMARGO, 2004).

Uma importante observação é efetuada por Mendonça (2001) quando destaca a influência da noção de sistemas em toda a produção da Geografia Física. A Teoria dos Sistemas deu-se principalmente ou inicialmente na "escola norte americana" durante os anos de 1950 e 1960 em associação com o método qualitativo recebendo a nomenclatura de "Geografia Quantitativa e Teorética”, está baseada em modelização, enfraqueceu de certo modo, a abordagem da natureza em associação a ação antrópica (MOREIRA, 1994; MENDONÇA, 2001).

Neste contexto, de introdução e inserção da Teoria dos Sistemas, a Biogeografia integra-se do modelo de ecossistemas, método de estudo da natureza específico da Biologia e da Ecologia e propõe-se a utilizá-lo em suas análises a partir do surgimento do termo biocenose, considerado por alguns Biogeógrafos como sinônimo de ecossistemas.

Muito embora a Biogeografia integre para si o conceito de ecossistema, esta não integrará para si a inserção da perspectiva social na análise geográfica. Mais uma vez, a Biogeografia se posicionará sob o enfoque exclusivamente natural da Ciência Geográfica e não assumirá seu posicionamento enquanto perspectiva biológica inserido em uma Ciência Social estritamente aplicada como a Geografia o é.

\section{A BIOGEOGRAFIA HOJE}

Atualmente, por questões didáticas, dentre as possíveis divisões da história da Biogeografia, a proposta de Furlan (2009) destaca três períodos: o Clássico, o Wallaceano e Moderno.

O período clássico compreende desde meados dos anos de 1760 a 1860 no qual os viajantes naturalistas voltavam suas pesquisas para a catalogação das espécies vegetais e animais. Desta forma, este primeiro período é caracterizado pela autora pelo início da catalogação e descrição das espécies.

Já no século seguinte, no período Wallaceano, compreende o século entre 1860 a 1960 muitos foram os avanços como a formulação e a publicação da teoria evolutiva das espécies elaborada por Charles Darwin e os conhecimentos de Wallace que muito contribuíram para os estudos da época, já que suas pesquisas consideravam elementos que exerciam influências sobre as mudanças de padrões distributivos e evolutivos das espécies (BROWN e LOMOLINO, 2006).

O terceiro período, Furlan (2009) denomina como moderno e inicia a partir de 1960, marcado por novos caminhos na pesquisa de Biogeografia e estudos de fatores limitantes a vida, tendo uma grande ascensão no que diz respeito aos avanços teóricos. Um marco importante foi a aceitação da teoria do movimento das placas tectônicas, que fez com que os estudiosos em Biogeografia repensassem e revisassem as teorias de distribuição das espécies. A partir disso, o foco passou a recair sobre temas voltados a "[...] questões sobre processos que determinam a diversidade da vida e o número de espécies que coexistem nos mesmos locais e habitats [...]" (BROWN e LOMOLINO, 2006 p. 34).

Com o passar de três séculos a Biogeografia foi se constituindo e se firmando enquanto Ciência, a qual contribui para estudos voltados à conservação da biodiversidade terrestre através das teorias biogeográficas. Esta Ciência pode ser dividida em zoogeografia e fitogeografia, a primeira ocupa-se em compreender a distribuição dos animais e as relações que estes mantém entre si e com o meio; enquanto que a segunda volta-se ao entendimento da espacialização de espécies vegetais bem como a sua interação com os demais elementos do ambiente (TROPPMAIR, 1933; CONTI e FURLAN, 2005).

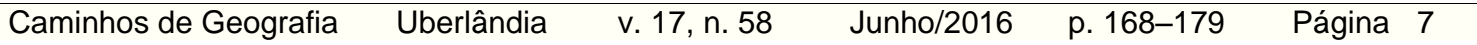


Embora didaticamente ainda se estruture os estudos e pesquisa em Biogeografia a partir destes dois focos de estudos (CAMARGO, 2004; ANDRADE, 2012), é importante considerar que tanto espécies animais ou vegetais não devam ser estudadas como elementos isolados e que não tenham relações, pois ambos evoluíram juntos.

Conforme destacam Valeri e Senô (2004) a ausência de um destes componentes torna-se inviável a vida dos demais uma vez que se tratam de relações intrínsecas e mútuas entre ambas, animais e vegetais (CONTI e FURLAN, 2005). Mais uma vez, retornamos a questão da complexidade das análises em Biogeografia que já se configuram na questão do ensino, ou seja, enquanto disciplina nos cursos de graduação em Geografia (SANTA ROSA e REIS JR., 2012).

“[...] não é possível aprofundar em um único semestre todos os campos da Biogeografia, tais como a Ecologia, Evolução, Geologia e até mesmo rever conteúdos da própria Geografia envolvidos na determinação dos padrões e processos responsáveis pela distribuição das plantas e dos animais" (FURLAN 2005, p. 12).

Portanto, entende-se que, de uma maneira mais ampla, os estudos em Biogeografia, desenvolvidos pela Ciência Geográfica, devem considerar as diferentes esferas terrestres: atmosfera, hidrosfera, litosfera, criosfera e como síntese se configura como biosfera, ou seja, a esfera da vida (Figura 1). A Biogeografia ao reunir conhecimentos de várias ciências é aquela que consegue combinar perfeitamente o âmbito social e natural possibilitando assim análises integradas do meio (CAMARGO, 2000).

Figura 1. Esferas terrestres.

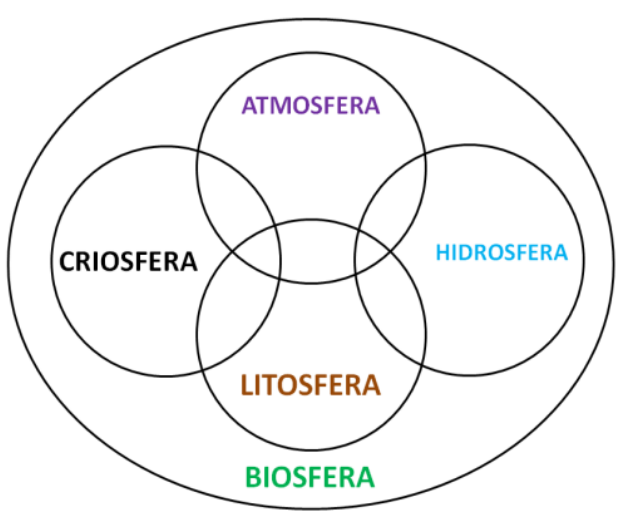

Fonte: autor

Neste contexto e retomando a classificação histórica de Furlan (2009) visualiza-se a possibilidade de inserção da componente geotecnológica no período atual da Biogeografia. Com o advento dos avanços oriundos de radares, imagens de satélite, sensores remotos e móveis e, principalmente softwares, a Biogeografia encontra nestas técnicas uma nova possibilidade de modernização e reinvenção frente as tecnologias presentes.

O mapear, identificar e localizar por meio das geotecnologias, possibilita ao Biogeógrafo estabelecer com maior praticidade as relações entre a natureza e a sociedades. Por meio do cruzamento de informações é possível analisar sob o foco biogeográfico as repercussões que se configuram no espaço e de como a sociedade atua, altera e modifica as relações existentes no meio.

As novas técnicas em geotecnologias, vai ao encontro de se desenvolver uma Biogeografia ampla que considera as diferentes esferas terrestres sem deixar de lado o seu caráter

$\begin{array}{llllll}\text { Caminhos de Geografia } & \text { Uberlândia } & \text { v. 17, n. } 58 & \text { Junho/2016 } & \text { p. 168-179 } & \text { Página } 8\end{array}$


enquanto Ciência Geográfica. A utilização desta novas técnicas que avançam nos cursos de graduação em Geografia possibilita uma nova roupagem aos estudos Biogeográficos. Ao utilizar mais uma ferramenta capaz de auxiliar na abordagem multidisciplinar e na união do conhecimentos das diferentes ciências combinando assim, o âmbito social e natural em suas análises integradas do meio.

Porém, o uso das geotecnologias vai de encontro com as práticas dos pesquisadores. Ainda se faz recente a utilização, uso e aplicabilidade de programas e softwares de mapeamento. Atualmente os docentes e pesquisadores das Universidades se encontram na iminência de apreender e só então utilizá-las em larga escala para as suas atividades de ensino, pesquisa e extensão. Não é raro o caso de docentes/pesquisadores com mais de 10 anos de Universidade que não faz uso ou, não dominam técnicas de mapeamento existentes por meio computacional.

Trata-se na verdade de um processo de transição, no qual as geotecnologias chegam as Universidades e os docentes tem que assimilar as mesmas aos seus conteúdos. Uma vez que - mercado de trabalho demanda essa nova técnica para os recém formados, seja na licenciatura com o professor utilizando por exemplo, ferramentas do Google Earth ou lousas digitais, seja no bacharelado, com o efetivo mapear por meio de softwares aplicados.

A cada ano novas tecnologias são lançadas o que possibilitaria no sentido de auxiliar nas pesquisas que, no caso do Brasil, ocorrem de modo maciço nas Universidades Públicas. Acredita-se que esse descompasso será e já está sendo sanado, com a perspectiva de novas frentes de pesquisas na temática de Biogeografia para os próximos anos.

Neste sentido, aponta-se as pesquisas desenvolvidas por Abreu e Coutinho (2014) e Cunha et al. (2015), apenas para citar exemplos da possibilidade do uso das geotecnologias na pesquisa sob o foco de índices, métrica e mapeamento da paisagem e cobertura vegetal. Por tanto, as geotecnologias vão ao encontro do avanço metodológico das análises biogeográficas.

Com relação aos avanços teóricos, aos biogeógrafos será necessário o estabelecimento e a abordagem de estudos e pesquisar que avancem na discussão dos aspectos naturais e em associação os aspectos sociais. Caberá principalmente aos biogeógrafos romper com a velha dicotomia de métodos e fundamentos científicos das ciências sociais e naturais em prol do desenvolvimento de uma biogeografia interdisciplinar e eminentemente geográfica.

O estudo de Sousa (1999) na valorização da biodiversidade, consequências da diversidade biológica e impactos na sociedade avança nesta perspectiva. Embora pautado em uma visão economicista da natureza, Sousa (1999) chama atenção para as causa primárias do desmatamento e as consequências para a sociedade. $O$ autor discute ainda, a valorização da biodiversidade destacando seus benefícios econômicos e estabelecendo uma análise que denominamos biogeográfica pautada na conservação e preservação ambiental.

\section{CONSIDERAÇÕES FINAIS}

Procuramos nesse breve artigo mostrar uma abordagem da gênese e do desenvolvimento da Biogeografia. Considerando o seio da sua gênese nos registros pré-históricos, ao longo de seu desenvolvimento, a Biogeografia enfrentou altos e baixos na sua produção científica, partindo de análises descritivas, sendo aprisionada por questões religiosas e encontrando, principalmente, nas ciências da natureza suas bases para seu desenvolvimento pleno na Ciência Geográfica.

De "Geografia das Plantas" para "Geografia Botânica" e até "Geografia da História Natural" é com Friedrich Ratzel que a Biogeografia recebe sua denominação ao mesmo tempo que desenvolve-se no âmago e na gênese da Ciência Geográfica.

Se por um lado a "escola francesa" partilhou a Ciência Geográfica e despertou nos diferentes enfoque natural da Geografia uma maior autonomia e emancipação perante as suas abordagens, despertou na Biogeografia uma aproximação com a Biologia e Ecologia (principalmente) que se arrastou pelos séculos seguintes e que the configurou as amarras que Ihe constituem até atualidade.

$\begin{array}{lllll}\text { Caminhos de Geografia } & \text { Uberlândia } & \text { v. 17, n. } 58 \quad \text { Junho/2016 } & \text { p. 168-179 } & \text { Página } 9\end{array}$


Ainda que os Geógrafos reconheçam que a Biogeografia possua diferentes faces, frente as suas diferentes abordagens, seja na Ciência Geográfica ou na Ciência Biológica, esta ultrapassa as referidas disciplinas e por não se constituir um campos exclusivo de uma ou outra, aumenta sua complexidade quando desenvolvida por estes ou outros profissionais. $O$ que nos remete a ideia de interdisciplinaridade na suas abordagens e portanto, complexifica 0 estudo da Biogeografia.

Embora seja reconhecido que a Biogeografia não tenha realmente um protagonismo na Ciência Geográfica Brasileira, parece-nos possível modificar esse quadro com a inserção das geotecnologias, avançando portanto, na perspectiva metodológica e, o retorno do arcabouço teórico para a inserção sistêmica e integradora avançando assim, na perspectiva teórica.

De modo algum projeta-se única e exclusivamente no uso de Geotecnologias para um desenvolver nos estudos e pesquisas em Biogeografia. Porém, a demanda que há, principalmente por parte dos discentes, do mercado de trabalho e da inserção de novas técnicas, softwares e programas nas Universidade, pode ser um dos fatores a ser considerado.

Destaca-se ainda, a necessidade do desenvolvimento e discussão no que compete as abordagens teóricas na perspectiva da Biogeografia na Ciência Geográfica. A ausência de um fórum nacional, como existente nas demais áreas - Simpósio Brasileiro de Climatologia Geográfica, Simpósio Nacional de Geomorfologia, Simpósio Nacional de Geografia Urbana, Simpósio Nacional de Geografia Agrária, entre outros - restringe a discussão de novas metodologias, técnicas e avanços teórico e conceituais nas abordagem da Biogeografia.

Embora seja surjam propostas regionais, como no caso Congresso Nacional de Educação Ambiental \& Encontro Nordestino de Biogeografia que ocorrerá no ano de 2016, no Nordeste do país, ou ainda, Workshop em diversas Instituições. Faz-se necessário um fórum nacional que integre, principalmente, Geógrafos que se dediquem aos estudos e pesquisas em biogeografia.

Visualiza-se que a Biogeografia é detentora de um potencial ramo da Ciência Geográfica, capaz de diminuir as antigas dicotomias desta ciência, por meio da utilização de técnicas contemporâneas e análises sistêmicas e integradas. A Biogeografia deve ser pensada e desenvolvida como uma componente híbrida, excluindo-se portanto a ênfase dada aos estudos da natureza ou da sociedade. Assim, cabendo portanto ao Geógrafo desenvolver suas análises na perspectiva eminentemente Geográfica.

\section{REFERÊNCIAS}

ABREU, K.M.P.; COUTINHO, L.C. Sensoriamento remoto aplicado ao estudo da vegetação com ênfase em índice de vegetação e métricas da paisagem. Vértices. Campos dos Goytacazes, Rio de Janeiro, vol.16, n.1, p. 173-198, jan./abr. 2014.

ALBUQUERQUE, E.S.; CANDIOTTO, L.Z.P.; CARRIJO, B.R.; MONASTIRSKY, L.B. A nova natureza do munso e a necessidade de uma biogeografia "social". Geosul. Florianópolis, vol. 19, n.38, p. 141-158, jul./dez. 2004.

ANDRADE, A.S.R. A Biogeografia na formação em Geografia nas Universidades Federais Brasileiras. Trabalho de Conclusão de Curso (Geografia) - Universidade de Brasília. 2012.

BROWN, J.H.; LOMOLINO, M.V. Biogeografia. 2. ed. Ribeirão Preto: FUNPEC, 2006.

CAMARGO, J.C.G. Evolução e Tendências do Pensamento Geográfico no Brasil: a Biogeografia. Tese de Livre-Docência, IGCE - UNESP, Rio Claro (SP), 1998.

CAMARGO, J.C.G. Uma análise da produção biogeográfica no âmbito de periódicos geográficos selecionados. Sociedade \& Natureza, Uberlândia, vol. 12, n.24, p. 33-45, jul. /dez. 2000.

CAMARGO, J.C.G. Uma análise da produção biogeográfica no âmbito de periódicos geográficos selecionados. Estudos Geográficos. Rio Claro, vol. 2, n.1, 2004, p. 87-106.

$\begin{array}{lllll}\text { Caminhos de Geografia } & \text { Uberlândia } & \text { v. 17, n. } 58 \quad \text { Junho/2016 } & \text { p. 168-179 } & \text { Página } 10\end{array}$


CARVALHO, C.J.B.; ALMEIDA, E.A.B. Biogeografia da América do Sul: padrões e processos - São Paulo: Roca, 2010.

CAMARGO, J.C.G.; TROPPMAIR, H. A evolução da Biogeografia no âmbito da ciência geográfica no Brasil. Revista Geografia. Rio Claro: AGETEO, vol. 27, n.3, 2002, p. 133-155.

CARVALHO, M.B. Novos fundamentos para a biogeografia: a revolução biotecnológica e a cartografia dos mananciais de bio-diversidade. In: RIBEIRO, H. (Org.). Olhares Geográficos: meio ambiente e saúde. 1ª̂ed.São Paulo: Senac, 2005, v. único, p. 15-30.

CONTI, J.B.; FURLAN, S.A. Geoecologia: o Clima, os Solos e a Biota. In: ROSS, J.L.S. Geografia do Brasil. 5. ed. rev. e ampl. São Paulo: Edusp, 2005.

CONWAY, W. A tecnologia pode ajudar na preservação das espécies? In: WILSON, E.O. Biodiversidade. Rio de Janeiro: Nova Fronteira, 1997.

CUNHA, E.L.; BACANI, V.M.; SAKAMOTO, A.Y. A utilização de imagem de alta resolução espacial para o mapeamento de uso da terra e cobertura vegetal. Geografia Ensino \& Pesquisa, vol. 19, n. 2, maio/ago. 2015.

D'HORTA, F.M. Sistemática Molecular e Filogeografia de Espécies do Gênero Sclerurus Swainson 1827 (Aves: Furnariidae): Investigando a História Biogeográfica da Mata Atlântica. Tese (Doutorado em Ciências Biológicas) - Instituto de Biociências - USP, São Paulo, 2009.

DROUIN, J.M. De Lineu a Darwin: os viajantes naturalistas. In: SERRES, M. (org.). Elementos para uma história das ciências II. Do fim da idade média a Lavoisier. Lisboa: Terramar, v. 2, 1996.

FURLAN, S.A. Projetos de estudo em biogeografia: uma abordagem significativa da construção de projetos. In: CASTELLAR, S. (Org.). Educação geográfica: teorias e práticas docentes. São Paulo: Contexto, 2005.

FURLAN, S.A. Técnicas de Biogeografia. In: VENTURI, L.A.B. (Org). Praticando Geografia Técnicas de Laboratório e Campo. São Paulo. Oficina de Textos. p. 99 - 130. 2009.

KUHLMANN, E. Noções de Biogeografia. Boletim geográfico. Rio de Janeiro, IBGE, v. 254, p. 48-111, 1977.

MENDONÇA, F. Geografia física: ciência humana? 7a. ed. São Paulo: Contexto, 2001.

MIRANDA, G.S.; DIAS, P.H.S. Biogeografia de vicariância: histórico e perspectivas da disciplina que lançou um novo olhar sobre a diversidade na Terra. Filosofia e História da Biologia, v. 7, n. 2, p. 215-240, 2012.

MOREIRA, R. O Que é Geografia. 14a. ed. São Paulo: Brasiliense, 1994.

NETO, D.P.; ALVES. F.D. Alexander Von Humboldt: viajante naturalista e entusiasta da harmonia da natureza. In: GODOY, P.R.T. (org.) História do pensamento geográfico e epistemologia em Geografia. São Paulo: Cultura Acadêmica, 2010.

PAPAVERO, N.; TEIXEIRA, D.M. Os viajantes e a biogeografia. In: MORRONE, J.J.; BOUSQUETS, J.L. (Org.). Una perspectiva Latinoamericana de la Biogeografia. 1ed. México, DF: Universidad Nacional Autónoma de México, 2003.

RATZEL, F. Geografia Dell'Uomo (Antropogeografia). Turim: Fratelli Bocca, 1914.

ROCHA, Y.T. Técnicas em Estudos Biogeográficos. Revista Raega. Curitiba. V. 23 p. 398-427.

SANTA ROSA, A.; REIS JR., D.F.C. Aspectos históricos e conceituais da biogeografia: Problemas de identidade e formação no Brasil. In: III Encontro Nacional de História do Pensamento Geográfico e I Encontro Nacional de Geografia Histórica, 2012, Rio de Janeiro. III ENHPG e I ENGH, 2012.

TROPPMAIR, H. Biogeografia e Meio Ambiente. 9. ed. Rio de Janeiro: Technical Books, 1933. 